\title{
Microstructure of the Alloys Prepared by Reduction of Deep Sea Nodules by Alu- minium and Silicon
}

Pavel Novák, Jakub Vlášek, Petr Dvořák, Andrea Školáková, Kateřina Nová, Anna Knaislová

University of Chemistry and Technology, Prague, Department of Metals and Corrosion Engineering, Technická 5, 16628 Prague 6, Czech Republic. E-mail: panovak@vscht.cz

Deep sea nodules are considered as an alternative and very rich source of several metals. Up to present days, the processing of these polymetallic ores is cosidered to be carried out by the extraction of individual metals. This work deals with the processing of the deep-sea nodules by metalothermic method by aluminium and silicon. The nodules are reduced complexely without the extraction of individual metals, forming the polymetallic alloys. Reduction was carried out in a small scale with the initiation in an electric resistance furnace. Microstructures of the formed alloys and the slag were described in dependence on the excess of the reduction agent against the stoichiometry. Even though both of the reduction agents are generally applicable, reduction by aluminium was proved to be more efficient and leads to more complex alloys.

Keywords: Deep sea nodules, Metallothermic reduction, Alloy, Microstructure

\section{Introduction}

Since the mineral resources on the Earth are limited, the deep sea nodules are considered as a potential source of many metals [1]. These polymetallic ores have a different composition in each location, but there is a large predominace of nodules based on manganese and containing also iron, copper, nickel, cobalt and other elements [1]. The deep sea nodules can be found on many regions in oceans usually in the depth of $3500-6500 \mathrm{~m}$. The most important locations of the nodules are Clarion-Clipperton Zone, Cook Islands Area, Peru Basin and Central Indian Ocean Ba$\sin [2]$. The already developed methods for the processing of these ores are based on extraction of individual elements [2]. These processes can yield individual metals, such as manganese or cobalt, with sufficient purity, but they are very costly as well as the mining process, thus causing the processing of deep sea nodules economically non-sustainable. There are also other applications of deep sea nodules being considered, such as sorbents, pigments or other chemical reagents $[3,4,5,6]$. Since there are many alloys containing manganese, iron and other constituents of nodules used on technical praxis $[7,8,9]$, a completely different approach was tested. The nodules were crushed and reduced as a complex ore by metallothermic reduction, testing the way to the production of completely new alloys, containing the elements in "natural“ proportions.

\section{Materials and Methods}

For the reduction process, the crushed deep-sea nodules from the Clarion-Clipperton zone of the $\mathrm{Pa}$ cific Ocean were used. The composition of the homogenized nodules determined by $\mathrm{X}$-ray fluorescence (XRF) analysis is shown in Tab. 1.

Tab. 1 Chemical composition of the milled and homogenized deep sea nodules

\begin{tabular}{|l|l|l|l|l|l|l|l|l|l|l|l|l|l|}
\hline Element & $\mathbf{M n}$ & $\mathbf{F e}$ & $\mathbf{S i}$ & $\mathbf{A l}$ & $\mathbf{M g}$ & $\mathbf{C a}$ & $\mathbf{N a}$ & $\mathbf{C u}$ & $\mathbf{N i}$ & $\mathbf{T i}$ & $\mathbf{Z n}$ & $\mathbf{C o}$ & $\mathbf{O}$ \\
\hline wt. \% & 30.57 & 4.41 & 3.53 & 2.16 & 1.87 & 1.84 & 1.64 & 1.18 & 1.14 & 0.35 & 0.14 & 0.13 & bal. \\
\hline
\end{tabular}

The crushed nodules were dried at $250{ }^{\circ} \mathrm{C}$ for $4 \mathrm{~h}$. Reduction of the deep sea nodules was carried out by aluminium and silicon in stoichiometric amount, which was calculated on the basis of the expected reduction of manganese, iron, copper, nickel, zinc and cobalt oxides, and with the excess of 20 and $40 \%$. The chemical composition of the mixtures is presented in Tab. 2. The reaction mixtures were compressed by the means of LabTest 5.250SP1-VM universal loading machine. The reduction was carried out at $1100{ }^{\circ} \mathrm{C}$.
The samples were placed to the preheated electric resistance furnace and kept at the temperature for $5 \mathrm{~min}$.

Tab. 2 Chemical composition of the reaction mixtures

\begin{tabular}{|c|c|c|c|}
\hline sample & nodules $\mathbf{( g )}$ & $\mathbf{A l} \mathbf{( g )}$ & Si $(g)$ \\
\hline $\mathrm{Al} 1$ & 2.03 & 0.47 & - \\
\hline $\mathrm{Al} 2$ & 1.96 & 0.54 & - \\
\hline $\mathrm{Al} 3$ & 1.89 & 0.61 & - \\
\hline $\mathrm{Si} 1$ & 2.12 & - & 0.38 \\
\hline $\mathrm{Si} 2$ & 2.06 & - & 0.44 \\
\hline $\mathrm{Si} 3$ & 2.00 & - & 0.50 \\
\hline
\end{tabular}


The phase composition of the samples was characterized by X-ray diffraction (XRD) by the means of PANalytical X'Pert Pro diffractometer with $\mathrm{Cu}$ anode. Microstructure was observed by scanning electron microscope (SEM) TESCAN VEGA 3 LMU with Oxford Instruments X-max $20 \mathrm{~mm}^{2}$ EDS analyser on the metallographic samples after grinding and polishing.

\section{Results and Discussion}

The XRD patterns of the samples reduced by aluminium are shown in Fig. 1. In all of the samples, there can be seen the constituents of the slag $\left(\mathrm{Al}_{2} \mathrm{O}_{3}\right.$, $\mathrm{FeAl}_{2} \mathrm{O}_{4}$ and $\left.\mathrm{Al}_{6} \mathrm{Si}_{12} \mathrm{O}_{13}\right)$. The metallic phase is represented by manganese, iron (in the case of the stoichiometric amount of aluminium) and manganese silicide $\left(\mathrm{Mn}_{3} \mathrm{Si}\right)$. There is also silicon carbide detected in the samples prepared with the excess of aluminium. Its formation is probably connected with the presence of carbon in the deep sea nodules, coming from the residues of prehistorical animals in the nodules. Carbon cannot be determined by XRF and hence it is not listed in Tab.1.

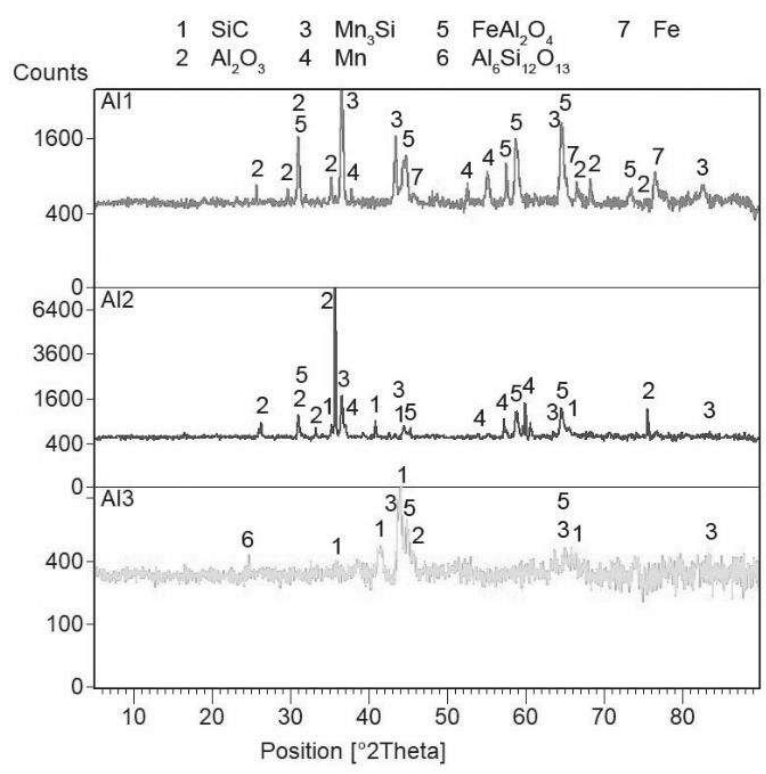

Fig. 1 XRD patterns of the samples reduced by aluminium

The chemical composition of the metallic phase observed in Fig.2 is summarized in Tab. 3. In the case of the Al1 sample, there are observed mostly the areas rich in manganese (see Tab. 3 and Fig. 2 a,b). In these areas, there is high content of silicon (up to $11 \mathrm{wt} . \%$ ), indicating the presence of silicide particles (Fig. 2a,b), which were identified by XRD as $\mathrm{Mn}_{3} \mathrm{Si}$, see Fig.1. In the structure of sample A2, there are visible particles of copper-rich phase and manganese phosphide, which were not identified by XRD. The reason is the low amount of these phases in total volume of the sample. In the case of the sample Al3, there are two completely different types of metallic areas (Tab. 3, Fig. 2c,d). One of them does not contain any detectable amount of aluminium, while the second one is based on aluminium and contains all of the reduced elements. This kind of segregation is probably a result of the small scale processing. It can be highly expected that in larger batch, the molten metallic phase will separate from the slag better and homogenize well. The aluminium-depleted regions contain manganese base solid solution, a phase rich in manganese and iron and containing also significant amount of silicon, and also the above mentioned copper-rich phase (Fig.2c). The aluminium-rich areas contain aluminium with traces of silicon and copper, aluminium-manganese phase and $\beta$-manganese (Fig.2d)

Tab. 3 Average chemical composition of the metallic phase in samples reduced by aluminium

\begin{tabular}{|c|c|c|c|c|}
\hline & Al1 & A12 & A13 & Al3 - Al rich \\
\hline $\mathrm{Mn}$ & 51.9 & 57 & 59.3 & 19.7 \\
\hline $\mathrm{Fe}$ & 15.8 & 18.9 & 14.6 & 1.7 \\
\hline $\mathrm{Al}$ & 11 & 0.4 & - & 69.7 \\
\hline $\mathrm{Si}$ & 10.6 & 7.5 & 16.4 & 6.7 \\
\hline $\mathrm{Ni}$ & 5.5 & 7.8 & 4.3 & 0.2 \\
\hline $\mathrm{Cu}$ & 5.2 & 8.4 & 5.4 & 2 \\
\hline
\end{tabular}

The slag in all of the samples reduced by aluminium is composed mostly of the sharp-edged particles of aluminium oxide (corrundum) and $\mathrm{FeAl}_{2} \mathrm{O}_{4}$ phase (Fig.3a), which contains many impurities such as sodium, potassium and calcium, as identified by EDS. In the materials $\mathrm{Al} 2$ and $\mathrm{Al} 3$, obtained by the reduction with the excess of aluminium (10 and 20\%), there are also large particles of silicon carbide $(\mathrm{SiC})$, see Fig. 3b. These particles probably originate from the reaction between silicon, reduced by aluminium, and residual organic stuff in the nodules.

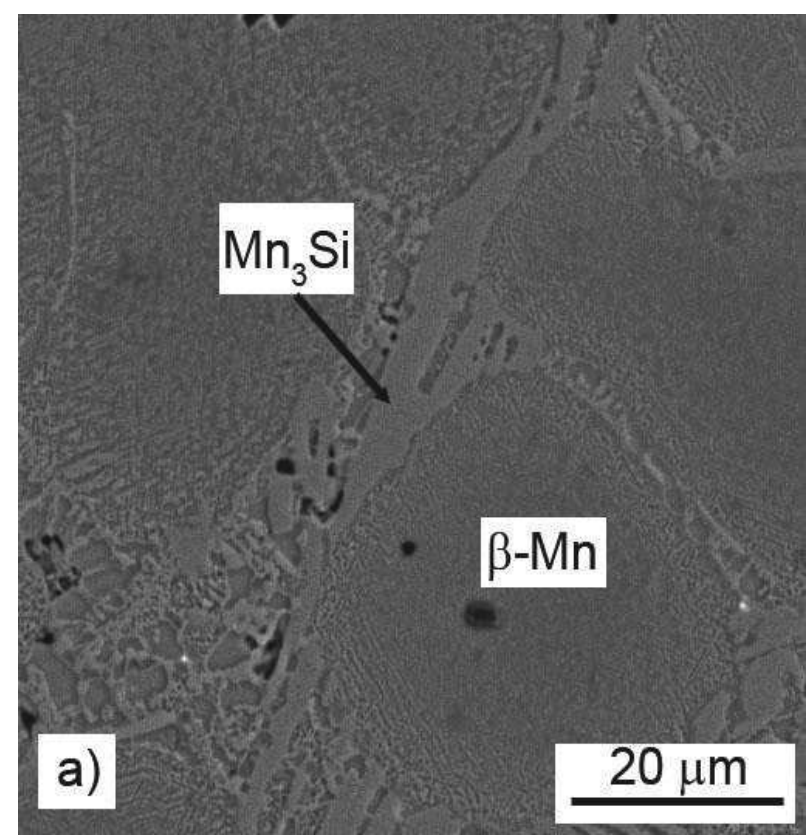



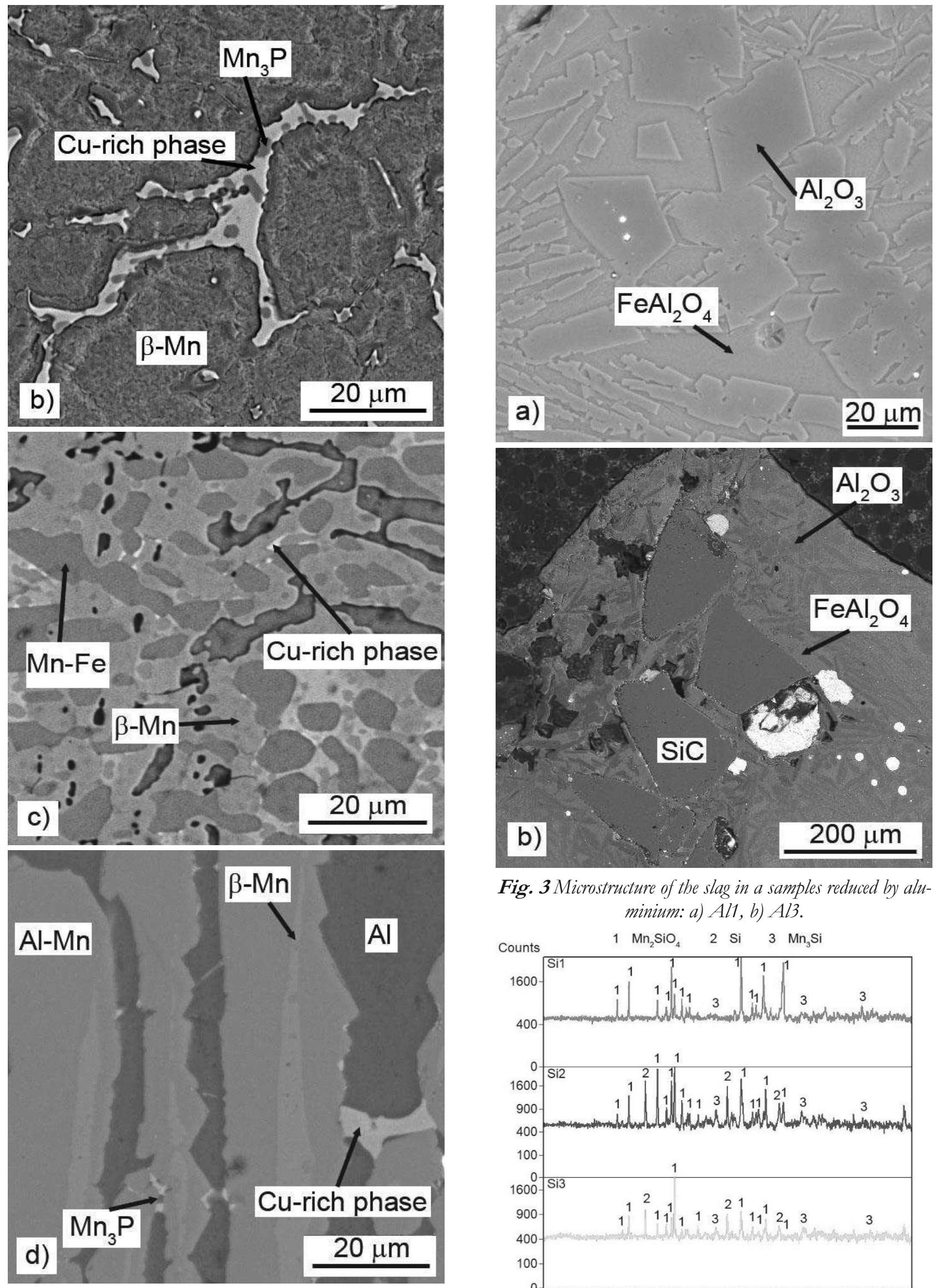

Fig. 3 Microstructure of the slag in a samples reduced by aluminium: a) Al1, b) Al3.

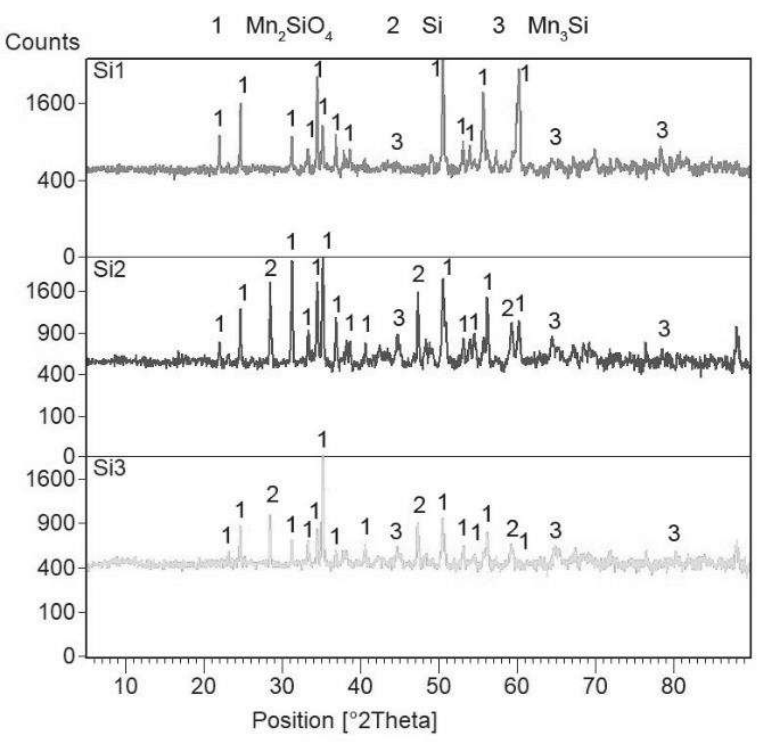

a) $A l 1, b) A l 2, c) A l 3$ - area with low amount of aluminium, d) $A l 3$ - area with bigh amount of aluminium.

Fig. 4 XRD patterns of the samples reduced by silicon 

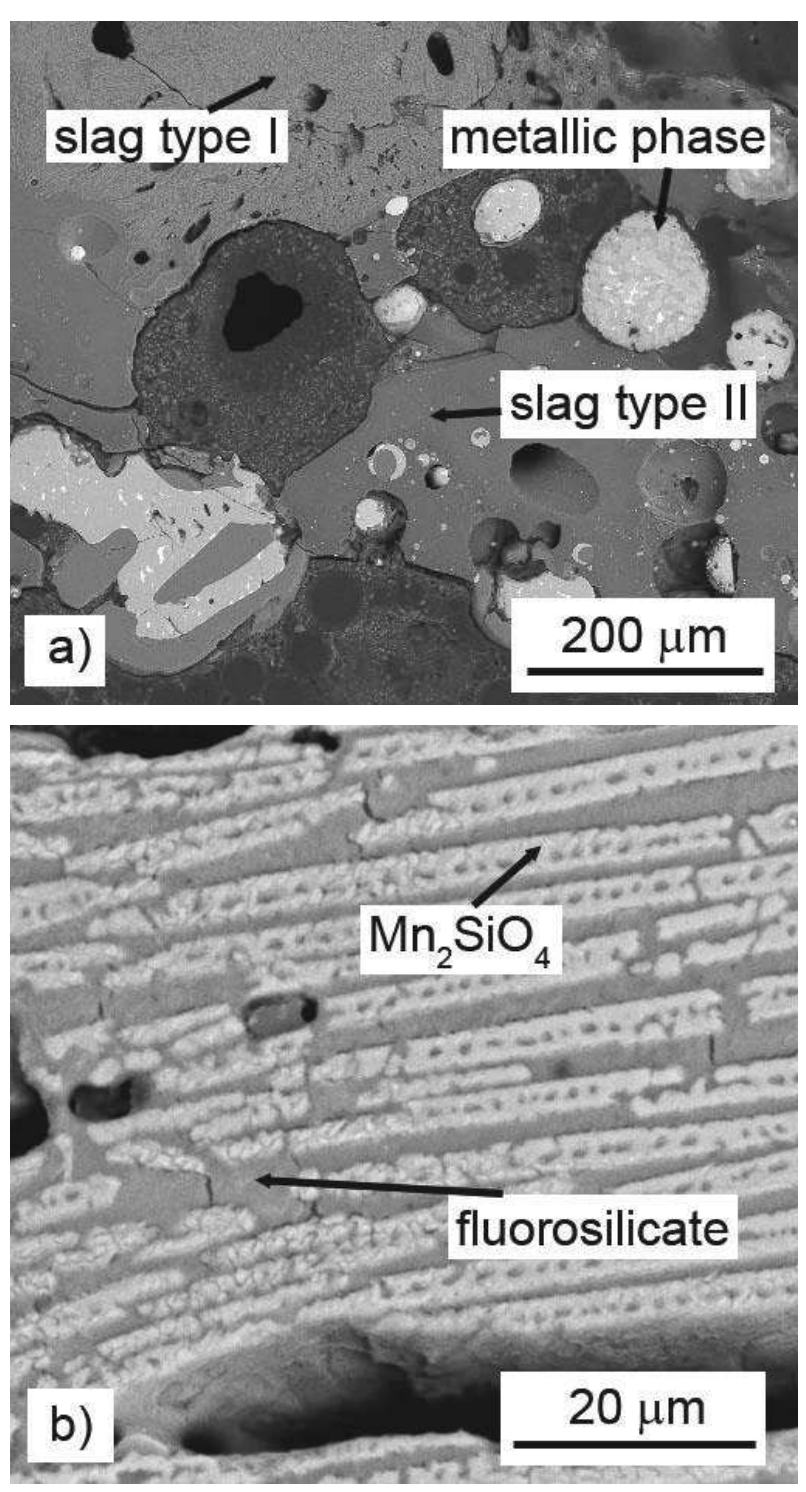

Fig. 5 Microstructure of the sample Si1 reduced by silicon (a), detail of the slag type I (b).

Tab. 4 Average chemical composition of the metallic phase in samples reduced by aluminium

\begin{tabular}{|c|c|c|c|}
\hline & Si1 & Si1 & Si3 \\
\hline $\mathrm{Mn}$ & 53.2 & 7.6 & 20.8 \\
\hline $\mathrm{Si}$ & 35.8 & 0.5 & 2.3 \\
\hline $\mathrm{Cu}$ & 6.5 & 11.1 & 10.8 \\
\hline $\mathrm{Fe}$ & 4.1 & 56.2 & 50.6 \\
\hline $\mathrm{Ni}$ & 0.5 & 17.7 & 14.9 \\
\hline $\mathrm{O}$ & - & 6.4 & - \\
\hline $\mathrm{Al}$ & - & 0.3 & - \\
\hline $\mathrm{P}$ & - & 0.2 & 0.6 \\
\hline
\end{tabular}

The XRD patterns of the samples reduced by silicon are shown in Fig.4. All of the samples contain the slag based on $\mathrm{Mn}_{2} \mathrm{SiO}_{4}$, according to the XRD. In fact, the slag is of two different types (Fig. 5 a). The slag type $\mathrm{I}$ is the mixture of crystalline $\mathrm{Mn}_{2} \mathrm{SiO}_{4}$ and probably amorphous fluorosilicate phase (Fig. 5 b). The slag type II is the fluorosilicate phase only.

The only metallic phase detected by XRD is the manganese silicide $\left(\mathrm{Mn}_{3} \mathrm{Si}\right)$. The samples with the excess of silicon used for reduction contain also residual silicon, according to XRD (Fig.4). According to the microstructure observation (Fig.5a) and the local chemical analysis by XRD, there are regions of the manganese silicide (darker) and the $\mathrm{Fe}-\mathrm{Mn}-\mathrm{Ni}$ rich areas (ligher) in the metallic phase of all silicon-reduced samples.

\section{Conclusion}

In this work, the feasibility of the reduction of deep sea nodules by aluminium and silicon was tested. It was found that both of the reduction agents are generally applicable. In the case of the reduction by silicon, the product was composed of the manganese silicide and iron-rich phase, probably the iron-based solid solution. The aluminium-reduced alloys were more complex, containing b-manganese, manganese prosphide and segregated copper-rich and aluminium-rich areas, depending on the aluminium content in the reduction mixture. In the case of the sample obtained with the use of the highes excess of aluminium, there were also large silicon carbide particles. In all of the samples, the metallic phase particles were small, surrounded of a large areas of the slag. In the case of the reduction by aluminium, the slag was based on aluminium oxide and $\mathrm{FeAl} 2 \mathrm{O} 4$. On the other hand, the silicothermic slag was based on $\mathrm{Mn}_{2} \mathrm{SiO}_{4}$ and fluorosilicate. The high degree of fragmentation of the metallic phase was probably caused by the small scale of the experiment. In future tests, the metallothermic reduction of deep sea nodules will be tested in larger volume and initiated by exothermic reactions.

\section{Acknowledgement}

This research was supported by Czech Science Foundation, project No. 20-15217S.

\section{References}

[1] HEIN, J. R., MIZELL, K., KOSCHINSKY, A., CONRAD, T. A. (2013). Deep-ocean mineral deposits as a source of critical metals for high-and green-technology applications: Comparison with land-based resources. In: Ore Geology Reviews, Vol. 51, pp. 1-14. Elsevier. Netherlands. ISSN: 0169-1368.

[2] SHARMA, R. (2017). Deep-Sea Mining: Resource Potential, Technical and Environmental Considerations, pp 23-63. Springer. Germany. ISBN: 9783-319-52557-0.

[3] PARIDA, K., SATAPATHY, P. K., DAS, N. (1996) Studies on Indian Ocean Manganese 
Nodules: IV. Adsorption of Some Bivalent Heavy Metal Ions onto Ferromanganese Nodules. In: Journal of Colloid and Interface Science, Vol. 181, No. 2, pp. 456-462. Elsevier. Netherlands.ISSN: 0021-9797.

[4] PARIDA, K. M., GORAI, B., DAS, N. N. (1997). Studies on Indian Ocean Manganese Nodules. In: Journal of Colloid and Interface Science, Vol. 187, No. 2, pp. 375-380. Elsevier. Netherlands.ISSN: 0021-9797.

[5] PARIDA, K. M., MOHANTY, S. (1998). Studies on Indian Ocean Manganese Nodules. VIII. Adsorption of Aqueous Phosphate on Ferromanganese Nodules. In: Journal of Colloid and Interface Science, Vol. 199, No. 1, pp. 22-27. Elsevier. Netherlands.ISSN: 0021-9797.

[6] PARIDA, K. M.; SAMAL, A.; DAS, N. N. (1998). Studies on Indian Ocean Manganese Nodules: 9. Catalytic Oxidation of Thiols to Disulphides by Central Indian Ocean Ferromanganese Nodules. In: Journal of Colloid and Interface
Science, Vol. 197, No. 2, pp. 236-241. Elsevier. Netherlands.ISSN: 0021-9797.

[7] KUČEROVÁ, L., JIRKOVÁ, H., VOLKMANNOVÁ, J., VRTÁČEK, J. (2018). Effect of Aluminium and Manganese Contents on the Microstructure Development of Forged and Annealed TRIP Steel. In: Manufacturing Technology, Vol. 18, No. 4, pp. 605-610. UJEP. Czech Republic. ISSN: 1213-2489.

[8] PODPROCKÁ, R., BOLIBRUCHOVÁ, D. (2018). The Role of Manganese in the Alloy Based on Al-Si-Mg with Higher Iron Content. In: Manufacturing Technology, Vol. 18, No. 4, pp. 650-654. UJEP. Czech Republic. ISSN: 12132489.

[9] GRZINCIC, G., LUKAC, I. (2014). Identification of Intermetallic Phases in the Alloy AlSi6Cu4. In: Manufacturing Technology, Vol. 14, No. 2, pp. 160-166. UJEP. Czech Republic. ISSN: 1213-2489. 